\title{
Enfrentamento do trabalho infantil pela Política de Assistência Social: o que há de novo no cenário ${ }^{1}$
}

Maria de Fatima Pereira Alberto. Universidade Federal da Paraíba

Ana Lúcia dos Santos França. Universidade Federal da Paraíba

Gustavo de Sousa Silva. Universidade Federal da Paraíba

Claudio Marques Trindade. Universidade Federal da Paraíba

Rebeca Kelly Gomes da Silva. Universidade Federal da Paraíba

\section{Resumo}

O objetivo deste artigo é analisar, no estado da Paraíba, o que há de novo na política de assistência social no enfrentamento do trabalho infantil. A pesquisa foi realizada em 10 municípios. Utilizou-se entrevista semiestruturada, análise de conteúdo temática e o SPSS. A amostra de 174 participantes foi composta em cada município por gestores, profissionais e usuários. Na compreensão dos gestores e profissionais o ministério e as secretarias municipais determinam ações socioassistenciais. Identificaram-se no desenho da política estratégias de articulação de políticas setoriais e de redes nos territórios, mas o que gestores e profissionais fazem são palestras e campanhas. Redes e articulações na prática não foram identificadas. $O$ enfrentamento do trabalho infantil pela política de assistência social não é visível para usuários. A política de assistência social é visível e procurada pelas necessidades dos adultos e da família e menos para crianças e adolescentes. Não há novo cenário de enfrentamento.

Palavras-chave: trabalho infantil; enfrentamento; política pública; assistência docial.

\section{Abstract}

Coping with child labor through the welfare policy: what is new in the scenario? The objective of this article is to analyze in the state of Paraiba what is new in the politics of social assistance in the confrontation of child labor. The research was carried out in 10 municipalities. Semi-structured interview, thematic content analysis and the SPSS were used. The sample of 174 participants was composed in each municipality by managing, professionals and users. In the understanding of the managers and professionals the ministry and the municipal secretaries determine socioassistential actions. Strategies for articulating sectoral policies and networks in the territories have been identified in the policy design, but what managers and professionals do are lectures and campaigns. Networks and joints in practice have not been identified. The confrontation of child labor with social assistance policy is not visible to users. The policy of social assistance is visible and sought after by the needs of adults and the family and less for children and adolescents. There is no new confrontation scenario.

Keywords: child labor; confrontation; public policy; social assistance.

\section{Resumen}

Enfrentamiento del trabajo infantil por la política de asistencia social: ¿qué hay de nuevo en el escenario?. El objetivo de este artículo es analizar en el estado de Paraíba lo que hay de nuevo en la política de asistencia social en el enfrentamiento del trabajo infantil. La investigación se realizó en 10 municipios. Se utilizó entrevista semiestructurada, análisis de contenido temático y el SPSS. La muestra de 174 participantes fue compuesta en cada municipio por gestores, profesionales y usuarios. En la comprensión de los gestores y profesionales el ministerio y las secretarías municipales determinan acciones socioasistenciales. Se identificaron en el diseño de la política estrategias de articulación de políticas sectoriales y de redes en los territorios, pero lo que gestores y profesionales hacen son charlas y campañas. Las redes y articulaciones en la práctica no han sido identificadas. El enfrentamiento del trabajo infantil por la política de asistencia social no es visible para los usuarios. La política de asistencia social es visible y buscada por las necesidades de los adultos y de la familia y menos para niños y adolescentes. No hay nuevo escenario de enfrentamiento.

Palabras clave: trabajo infantil; afrontamiento; política pública; asistencia social. 
O objetivo deste artigo é analisar, no estado da Paraíba, o que há de novo na política de assistência social no enfrentamento do trabalho infantil. O que se justifica considerando-se as mudanças empreendidas na política de enfrentamento desde 2005 com a junção do Programa Bolsa-Família, redesenhada em 2009 e consolidada em 2013 quando a Resolução 008 do Ministério de Desenvolvimento Social (MDS, 2013) extinguiu o Programa de Erradicação do Trabalho Infantil (PETI) e traçou um reordenamento da política de assistência social.

$\mathrm{Na}$ tentativa de combater o trabalho infantil e garantir a proteção de crianças/adolescentes, o Brasil iniciou, em 1996, o Programa de Erradicação do Trabalho Infantil (PETI), cujo principal objetivo era retirar crianças e adolescentes entre 7 e 15 anos de idade, de trabalhos considerados penosos, perigosos, degradantes ou insalubres e que colocassem em risco o desenvolvimento e a saúde dos mesmos (MDS, 2004). Desde sua criação, o PETI "consolidou-se e desenvolveu-se de forma integrada pelos entes federados, com ações de transferência de renda, trabalho social com as famílias e oferta de atividades socioeducativas para crianças e adolescentes retirados do trabalho" (MDS, 2010a, p. 11).

O PETI tinha como objetivos: facilitar o acesso, o bom desempenho e a permanência das crianças e adolescentes na escola; proporcionar complementação na renda mensal das famílias (Bolsa criança Cidadã); implantar atividades complementares à escola (Jornada Ampliada); oferecer orientação e apoio às famílias integrantes do programa; e promover geração de renda e qualificação profissional com as famílias (Ministério da Previdência e Assistência social [MPAS], 2001).

Em 2005, o PETI sofreu uma mudança ao ser integrado ao Programa Bolsa-Família (PBF) e ao Sistema Único de Assistência Social (SUAS), com a justificativa de aumentar a cobertura do atendimento, aprimorar e racionalizar os processos de gestão e garantir proteção e amparo aos adolescentes em situação de risco e suas famílias (Rua, 2007). Criado em 09 de janeiro de 2004, pela Lei $\mathrm{n}^{\circ} 10.836$, o PBF se configura como uma política intersetorial para enfrentar a pobreza e promover o desenvolvimento das famílias que se encontram em situações de vulnerabilidade socioeconômica, entre elas aquelas que apresentam situação de trabalho infantil (MDS, 2005).

A alteração modificou o modelo original do PETI. Deixou de ser um programa de renda mínima, característico das políticas sociais da década de 1990, que articulava as temáticas da pobreza, da fome com a educação e a transferência de renda (Silva, Yaszbek, \& Giovanni, 2008), para ser inserido no Bolsa-Família e se transformar em um programa cujo foco é a "indigência e o aumento do poder de compra" (Behring \& Boschetti, 2011, p. 185).

Permanecem com o PETI os municípios definidos pelo MDS com alta incidência de trabalho infantil (Artigo 15 da Resolução 008 de 18 de abril de 2013). O MDS considerou para tal os municípios com mais de 1.000 casos de trabalho infantil no Censo 2010; crescimento de 200 casos de 2000 para 2010 ou quando no exercício de 2014, constatou-se mais de 500 casos (MDS, 2013).

No novo modelo do PETI, as crianças e adolescentes retirados do trabalho precoce foram inseridos no Serviço de Convivência e Fortalecimento de Vínculos (SCFV) e a sua participação no serviço tornou-se uma condicionalidade para permanência no programa. Isso visando à prevenção de reincidência na prática do trabalho infantil (MDS, 2010a). De acordo com a Tipificação Nacional de Serviços Socioassistenciais, o SCFV atende crianças e adolescentes de 6 a 15 anos de idade visando à promoção de "trocas culturais e de vivência entre pessoas, fortalecendo os vínculos familiares e sociais, incentivando a participação social, o convívio familiar e comunitário e trabalhando o desenvolvimento do sentimento de pertença e identidade" (MDS, 2010a, p. 41). Participam do SCFV, dentre outras crianças e adolescentes, pessoas com deficiência, vítimas de violações de direito, porém, os egressos do trabalho infantil são definidos como possuindo prioridade (MDS, 2010a).

No cerne da proteção social básica o SCFV deve se articular com a Rede do Sistema de Garantia de Direitos (SGD) para ter sua ação potencializada. Essa articulação incorpora ações das políticas setoriais de assistência social, educação, saúde, cultura (MDS, 2010b) e da rede socioassistencial: "serviços, programas, projetos, benefícios ofertados pelos entes públicos e pelas entidades e organizações de assistência social" (MDS, 2013, p. 2).

O SCFV é ofertado no Centro de Referência de Assistência Social - CRAS (MDS, 2010b), que é uma unidade pública estatal que atua no âmbito da proteção básica, com o objetivo de prevenir a ocorrência de riscos sociais e situações de vulnerabilidade, inclusive referentes ao trabalho infantil, através do desenvolvimento de potencialidades, do fortalecimento de vínculos familiares e sociais e ampliação do acesso aos direitos de cidadania (MDS, 2009). Suas principais atribuições são: informar e orientar a população de seu território, encaminhar a população para outras políticas públicas e sociais, realizar o mapeamento e organização da rede de assistência social, inserir as famílias nos serviços da rede (Monteiro, 2011). 
Nesse contexto, a formação profissional das equipes que atuam no SCFV é de suma importância, sendo a capacitação dessas equipes um processo permanente de aquisição de saberes formais e informais, cabendo ao Governo Federal, aos estados e aos municípios apoiar e desenvolver ações para capacitar os trabalhadores do SUAS. As atividades de capacitação ofertadas devem ser norteadas pela apresentação dos padrões conceituais, metodológicos e operacionais do serviço (MDS, 2010a). Os temas recomendados para serem trabalhados perpassam as ações de convivência e as atividades desenvolvidas no serviço, devem ser flexíveis e abordar as questões presentes no território, na realidade sociocultural e na vivência pessoal, familiar e social das crianças e adolescentes. Os temas sugeridos para serem abordados são: infância-adolescência e direitos humanos, saúde, meio ambiente, cultura, lazer, esporte, ludicidade e brincadeiras e trabalho (MDS, 2010a).

A articulação da rede intersetorial e socioassistencial via CRAS deve contemplar o estabelecimento de alianças, contatos, encaminhamentos e fluxos de informação das unidades dos CRAS com os órgãos de proteção social básica existentes em cada território, sendo o coordenador do CRAS responsável pela articulação da rede de proteção social básica local, como pela organização das "reuniões periódicas com as instituições que compõem a rede" (MDS, 2009, p. 22), cuja equipe deve ser formada por assistentes sociais, pedagogos e psicólogos. Nesse contexto, as mudanças ocorridas no âmbito das políticas sociais, em especial na assistência social, abriram as portas para a inserção dos profissionais de psicologia na política de proteção social básica (Dantas \& Oliveira, 2014). Com o novo modelo, a política determina que os profissionais sejam capacitados para estabelecimento de rotina de acoIhimento e atendimento às famílias, traçar ações estratégicas e procedimentos para atender às demandas e fortalecer a potencialidade do território.

Assim as Ações Estratégicas do PETI (AEPETI) no âmbito do SUAS passaram a se estruturar em cinco eixos: (1) O eixo de Informação e Mobilização com ações de sensibilização, mobilização social, campanhas socioeducativas; e apoio e acompanhamento de audiências públicas que visem erradicar o trabalho infantil. (2) O eixo de Identificação corresponde às ações de: busca ativa e identificação dos casos de trabalho infantil e registro obrigatório das famílias, crianças e adolescentes no Cadastro Único para Programas Sociais do Governo Federal. (3) O eixo de Proteção Social contemplando ações de transferência de renda, inserção em serviços socioassistenciais, encaminhamento a outras políticas e programas e para ações de inclusão produtiva. (4) O eixo de Defesa e Responsabilização deve incluir ações de articulação com a rede de proteção (Superintendências, Agências Regionais do Trabalho, Conselho Tutelar etc.), e o acompanhamento das famílias em medidas protetivas. (5) O eixo de Monitoramento a que compete o registro de crianças/ adolescentes no sistema de informação do PETI, e o monitoramento em si (MDS, 2013).

As pesquisas sobre o PETI (Alberto, Pessoa, Costa, Belém, \& Silva, 2016) mostram que há semeIhanças quanto ao perfil dos participantes com maioria dos educandos, e famílias do sexo feminino e a maioria se considera de etnia negros, morenos e mulatos e cursou Ensino Fundamental. De modo semelhante Alberto, Viana, Santos, Patriota e Bittencourt (2017) também identificaram em estudo sobre o PETI que o perfil de educandos $(52,7 \%)$, famílias $(89,5 \%)$, educadores sociais $(68,3 \%)$, equipe técnica $(84,2 \%)$ e professores $(85,5 \%)$, a maioria é do sexo feminino. Quanto à etnia, a maioria dos educandos (44,9\%) e famílias $(43,5 \%)$ se autodefiniu como morena, enquanto a maioria da equipe técnica $(49,1 \%)$ e dos professores $(36,1 \%)$, como branca. No quesito escolaridade educandos e famílias apresentaram Ensino Fundamental incompleto; educadores sociais, Ensino Médio; e equipe técnica e professores, superior completo e pós-graduação, respectivamente.

As pesquisas sobre perfil demonstram similaridades ou proximidades quanto ao sexo entre educandos, famílias, educadores, equipe técnica e professores, ao mesmo tempo demonstram diferenças na escolaridade de modo que equipe técnica e professores têm formação de nível superior enquanto educandos e famílias têm fundamental incompleto. Mas a literatura (Bonamigo et al., 2015; Cacciamalli, Tatei, \& Batista, 2010; Gouveia, 2013) sobre o PETI também demonstra semelhança na análise da eficiência e eficácia do PETI, e da junção com o PBF revela a inadequação desses programas para enfrentar o trabalho infantil.

Para Gouveia (2013), a inserção de crianças e adolescentes no PETI produz mudanças positivas na vida, no comportamento, aprendizado e rendimento escolar, e até mesmo na socialização dos educandos. Já no que se refere à adequação do CRAS para enfrentar o trabaIho infantil, Gouveia (2013), em pesquisa que avaliou a eficácia e efetividade do PETI na perspectiva dos usuários e agentes do PETI, identificou que a grande maioria 
dos usuários apresentou um posicionamento positivo do programa e de seus profissionais. Porém, entre os agentes se observou um grau se satisfação menor, pois seu posicionamento tinha por base os resultados alcançados pelo programa e a avaliação das dificuldades que impediam a realização adequada dos trabalhos. Nessa linha das dificuldades, Romagnoli (2018) identifica que a relação das famílias e a equipe do CRAS é um desafio à promoção social.

Ao investigarem a junção do PETI com o PBF, Cacciamalli et al. (2010) e Cavalcanti, Costa e Silva (2013) identificam que o programa é eficiente para elevar o atendimento escolar, mas incapaz de reduzir o trabalho infantil. Bonamigo et al. (2015) analisam que a integração possibilitou ampliação das atividades socioeducativas, a convivência de crianças e adolescentes, egressos ou não do trabalho infantil, mas não enfrenta o trabalho infantil, pois retornam ao trabalho quando suas famílias necessitam, não havendo uma tessitura de Rede por parte do programa. Outros autores que pesquisam a política de assistência social identificam dificuldades e desafios na proteção integral dos direitos de crianças e adolescentes (Mendonça, 2002), da articulação e da intersetorialidade entre políticas sociais (Bichir, 2016; Carmo \& Guizardi, 2017). Alberto e Yamamoto (2017) analisam que a substituição do PETI pelo SCFV resultou de uma mudança no modelo de política pelo Brasil. Retirou o foco do trabalho infantil e da educação com o PETI e substituiu pelo foco na pobreza e na socioassistência com o SCFV.

\section{Metodologia}

\section{Lócus da Pesquisa}

A pesquisa foi realizada em 10 municípios do estado da Paraíba. A escolha dos municípios obedeceu a três critérios: (1) municípios onde havia sido feita pesquisa em 2009 e 2011 sobre o PETI e os resultados indicaram aumento da frequência escolar, mas não erradicação do trabalho infantil (Alberto et al., 2017); (2) municípios que possuíam políticas de formação profissional para os jovens; (3) municípios que pactuaram o PETI (depois das mudanças na configuração do referido programa, estabelecidas pela Resolução 008, de abril de 2013, do Conselho Nacional de Assistência Social - CNAS. Os municípios que atendiam, no mínimo, a dois desses critérios foram selecionadas para a realização do estudo: João Pessoa, Campina Grande, Patos, Sousa, Cajazeiras, Santa Rita, Sapé, Cuité, Esperança e Bayeux.

\section{Participantes e Amostra}

Nesse contexto, utilizaram-se como base para o presente estudo os dados do trabalho infantil na Paraíba, da PNAD 2009, que eram de 69.000 (Procuradoria Regional do Trabalho - $7^{\text {a }}$ Região, 2009), e se decidiu que a amostra total seria equivalente a $1 \%$ de 69.000 , ou seja, 690 participantes. Estes foram divididos nos 10 municípios entre gestores, profissionais e usuários dos serviços, programas e equipamentos das políticas de Assistência Social, Saúde, Formação Profissional para Jovens e Educação. Em cada município a amostra por política seria de 18 questionários, sendo quatro gestores, seis profissionais e oito usuários. A amostra da Política de Assistência Social retratada neste artigo compreendeu 33 gestores, 65 profissionais e 76 usuários, totalizando 174 participantes do Centro de Referência de Assistência Social (CRAS) e do Serviço de Convivência e Fortalecimento de Vínculos (SCFV).

\section{Técnica e Instrumento de Coleta de Dados}

No presente estudo, utilizou-se um questionário contemplando duas partes: questões abertas e fechadas. O questionário possuía dois formatos, sendo um para gestores/coordenadores e profissionais do CRAS e o outro, para os usuários dos serviços ofertados pelo CRAS. Ambos possuíam questões abertas e fechadas. Estas últimas continham questões de única e de múltipla escolha.

O questionário destinado aos gestores/coordenadores e profissionais versavam sobre os dados biossociodemográficos; capacitação de gestores e profissionais para atuar no serviço; estratégias e ações determinadas pelo MDS; estratégias e ações desenvolvidas pela secretaria de assistência social do município; estratégias e ações utilizadas pelo CRAS e SCFV, para enfrentar o trabalho infantil. O questionário direcionado aos usuários versava sobre os dados biossociodemográficos; a participação dos usuários nos serviços e programas oferecidos pelo CRAS e SCFV; atuação do CRAS e do SCFV para enfrentar o trabalho infantil.

\section{Procedimentos}

De posse dos termos de anuência da Secretaria de Desenvolvimento Humano do Estado, o projeto de pesquisa foi submetido ao Comitê de Ética em Pesquisa com Seres Humanos do Centro de Ciências e Saúde da UFPB. Após a obtenção de parecer positivo (CAAE 42623615.5.0000.5188) para a realização do estudo, os pesquisadores entraram em contato com as Secretarias de Assistência Social de cada município. Uma vez concedidas as autorizações, procedeu-se 
as visitas às unidades do CRAS e SCFV e aos usuários do referido serviço. Na visita os pesquisadores apresentavam a pesquisa para os gestores/coordenadores, profissionais e usuários. Após convite para participar e mediante assinatura do Termo de Consentimento Livre e Esclarecido, iniciava-se a aplicação do questionário.

\section{Análise dos Dados}

As questões abertas foram categorizadas usando-se a técnica de validação por dois juízes, ambos previamente treinados para tal. Após a categorização, tanto as questões fechadas como as abertas foram inseridas no software SPSS para uma análise estatística. Extraíram-se as frequências e porcentagens e procedeu-se à análise descritiva. Há várias questões de múltipla escolha, motivo pelo qual algumas vezes os dados nas tabelas não totalizam $100 \%$. Ao longo da descrição serão assinaladas tais questões.

\section{Resultados}

\section{Municípios}

Embora o desenho metodológico previsse a participação equitativamente semelhante de cada segmento (quatro gestores, seis profissionais e oito usuários) de participantes por município, isso não foi possível na sua totalidade. Entretanto, a realidade encontrada pelos pesquisadores nos municípios revelou que nem sempre era possível a obtenção dessa amostra por segmento, pois havia cidades com realidades completamente distintas, tais como: o número de equipamentos e a proporção de profissionais era variável; os serviços, equipamentos ou programas haviam sido fechados ou encerrados. Havia municípios de maior porte, como é o caso de João Pessoa, que é capital, que dispunha de mais equipamentos e serviços. Percebe-se que os municípios com pelo menos quatro gestores e seis profissionais dispõem de no mínimo dois CRAS e SCFV, ou seja, dos 10 municípios, pelo menos oito deles têm dois CRAS e todos têm SCFV, equipamentos e serviços necessários para atendimento a crianças e adolescentes em situação de trabalho infantil. Houve municípios em que não foi possível entrevistar nenhum usuário. As dificuldades decorreram também de recusas de participação com receio de retaliações, aspectos concernentes à dinâmica da política de caráter assistencialista que ainda se faz presente em alguns municípios.

\section{Dados Biossociodemográficos de Gestores, Profissionais e Usuários}

No que se refere à etnia (Tabela 1) houve uma variação, pois, a maioria dos gestores $(63,6 \%)$ e profissionais $(44,6 \%)$ se autodeclara como sendo pardos, enquanto que a prevalência entre os usuários foi de morenos (32,9\%). Entre gestores e profissionais, em segundo lugar se sobressaem brancos com pouco mais de $20 \%$. Mas, entre usuários, o segundo lugar é ocupado por pardos. Todavia, se em cada segmento de participantes somar-se pardo com negro, no caso dos gestores; pardo, negro e moreno, no caso dos profissionais; moreno, pardo, negro, preto e mulato no caso dos usuários, verifica-se que em todos os segmentos são mais de $70 \%$ da amostra composta de afrodescendentes.

Tabela 1. Dados Sociodemográficos dos Participantes da Pesquisa

\begin{tabular}{|c|c|c|c|c|c|c|c|c|}
\hline \multicolumn{9}{|c|}{ Etnia } \\
\hline Gestor & $\mathbf{F}$ & $\%$ & Profissionais & $\mathbf{F}$ & $\%$ & Usuários & $\mathbf{F}$ & $\%$ \\
\hline Pardo & 21 & 63,6 & Pardo & 29 & 44,6 & Moreno & 25 & 32,9 \\
\hline Branco & 7 & 21,2 & Branco & 18 & 27,7 & Pardo & 21 & 27,6 \\
\hline Negro & 3 & 9,1 & Negro & 11 & 16,9 & Branco & 19 & 25,0 \\
\hline Amarelo & 2 & 6,1 & Moreno & 6 & 9,2 & Negro & 7 & 9,2 \\
\hline \multirow[t]{5}{*}{ Total } & 33 & 100,0 & Amarelo & 1 & 1,5 & Amarelo & 1 & 1,3 \\
\hline & & & Total & 65 & 100,0 & Preto & 1 & 1,3 \\
\hline & & & & & & Mulato & 1 & 1,3 \\
\hline & & & & & & Claro & 1 & 1,3 \\
\hline & & & & & & Total & 76 & 100,0 \\
\hline
\end{tabular}


Tabela 1. Continuação

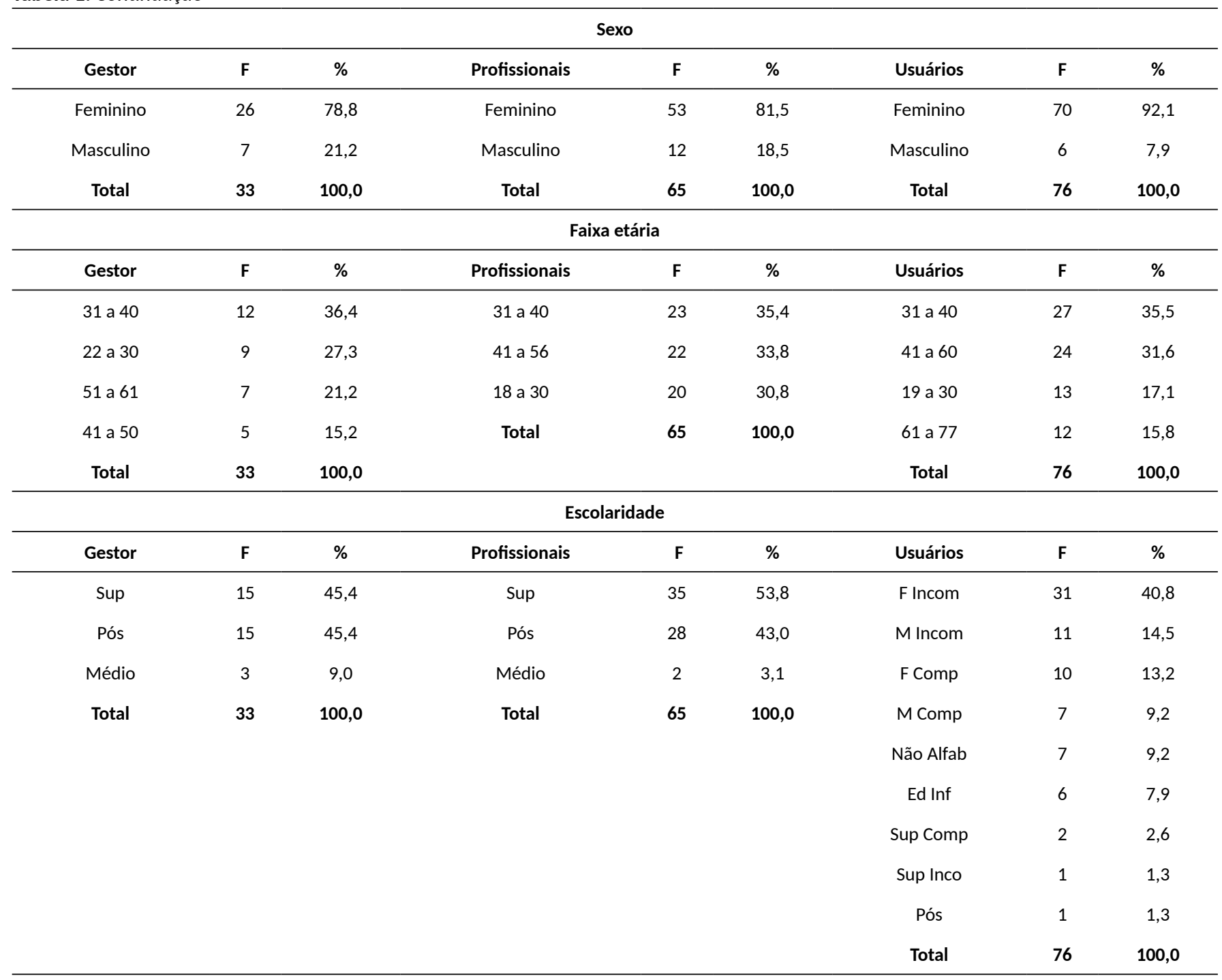

Fonte: Pesquisa Direta, 2016/2017.

Prevaleceu o sexo feminino nos três grupos: gestores, $78,8 \%$; profissionais, $81,5 \%$; e usuários, $92,1 \%$; bem como a faixa etária de 31 a 40 anos: gestores, $36,4 \%$; profissionais, $35,4 \%$; e usuários, $35,5 \%$. Na categoria escolaridade (Tabela 1), 53,8\% dos profissionais e $45,5 \%$ dos gestores possuem graduação. Entretanto, $9,1 \%$ dos gestores e 3,1\% dos profissionais têm apenas o Ensino Médio. Causa estranheza a existência de gestores com apenas Ensino Médio. Já quanto à escolaridade dos usuários, observou-se que a maioria, 40,8\% possuem o Ensino Fundamental incompleto, enquanto 9,2\% não são alfabetizados, 7,9\% possuem a Educação Infantil, 2,6\% possuem o Ensino Superior completo, e 1,3\% possui pós-graduação. Dentre os gestores do CRAS com graduação, a maioria $(30,3 \%)$ é formada em Psicologia, porém, entre os profissionais o curso predominante é o de Serviço Social com 41,5\%.

\section{Ações do CRAS e SCFV para o Enfrentamento ao Trabalho Infantil}

Capacitação dos gestores e profissionais. A maioria informou, em questão de múltipla escolha, que recebeu capacitação para atuar nos equipamentos e serviços: gestores, $72,7 \%$ e profissionais, $64,6 \%$. Segundo $39,4 \%$ dos gestores e $38,5 \%$ dos profissionais, essas capacitações frequentemente são realizadas em forma de palestras. Em relação aos temas mais trabalhados (Tabela 2), as respostas dos dois grupos divergiram, pois, se para a maioria dos gestores o tema mais abordado foi o trabalho infantil $(24,2 \%)$, para a maioria dos 
profissionais foi o SUAS $(35,4 \%)$. Para os profissionais, trabalho infantil $(21,5 \%)$ ficou em segundo lugar e exploração sexual em terceiro. Percebe-se (Tabela 2) que, embora os profissionais destaquem mais do que os gestores, os temas trabalho infantil e exploração sexual, sobressaem para ambos os temas concernentes à gestão: SUAS, Reordenamento dos serviços, SCFV, PBF, CRAS, Relatório Social, INSS, BPC. Os dados revelam nas ofertas de capacitações a maior preocupação com a gestão.

Tabela 2. Temas Trabalhados nas Capacitações

\begin{tabular}{|c|c|c|c|c|c|}
\hline \multirow{2}{*}{$\begin{array}{l}\text { Gestor } \\
\text { Temas }\end{array}$} & \multirow{2}{*}{$\mathbf{F}$} & \multirow{2}{*}{$\%$} & \multirow{2}{*}{$\begin{array}{c}\text { Profissionais } \\
\text { Temas }\end{array}$} & \multirow{2}{*}{$\mathbf{F}$} & \multirow{2}{*}{$\%$} \\
\hline & & & & & \\
\hline Trabalho infantil & 8 & 24,2 & SUAS & 23 & 35,4 \\
\hline $\begin{array}{l}\text { Reordenamento } \\
\text { dos serviços }\end{array}$ & 5 & 15,2 & Outros & 19 & 29,2 \\
\hline SCFV & 5 & 15,2 & Trabalho infantil & 14 & 21,5 \\
\hline Outros & 5 & 15,2 & Exploração sexual & 10 & 15,4 \\
\hline PBF & 3 & 9,1 & SCFV & 10 & 15,4 \\
\hline CRAS & 3 & 9,1 & $\begin{array}{l}\text { Reordenamento dos } \\
\text { serviços }\end{array}$ & 4 & 6,2 \\
\hline $\begin{array}{l}\text { Trabalho em } \\
\text { rede }\end{array}$ & 3 & 9,1 & $\mathrm{BPC}$ & 3 & 4,6 \\
\hline $\begin{array}{l}\text { Relatórios } \\
\text { sociais }\end{array}$ & 3 & 9,1 & Trabalho em rede & 3 & 4,6 \\
\hline INSS & 2 & 6,1 & PBF & 3 & 4,6 \\
\hline $\mathrm{BPC}$ & 2 & 6,1 & $\begin{array}{l}\text { Políticas públicas } \\
\text { para mulheres }\end{array}$ & 2 & 3,1 \\
\hline
\end{tabular}

Fonte: Pesquisa Direta, 2016/2017.

\section{Estratégias de enfrentamento: MDS, Secretaria de Assistência Social e CRAS}

Os participantes gestores e profissionais foram indagados, através de questões de múltipla escoIha, acerca de quais eram as recomendações do MDS, as estratégias das Secretarias Municipais de Assistência Social e dos CRAS para enfrentamento ao trabalho infantil. Considerando-se um ponto de corte de respostas até $20 \%$, identificou-se que de um modo geral os participantes apresentam quase o mesmo conjunto de estratégias (Tabela 3). Mas elas variam no destaque para cada setor (MDS, Secretaria Municipal e CRAS) e na ordem de importância entre gestores e profissionais.

No caso do Ministério e das Secretarias Municipais, os participantes gestores e profissionais apontaram a estratégia de inserção no SCFV e no PETI. Enquanto no CRAS as estratégias que se sobressaíram foram campanhas socioeducativas (gestores, $72,7 \%$; profissionais, $40 \%$ ) e palestras (profissionais, $52,3 \%$; gestores, $48,8 \%$ ), conforme pode ser visto na Tabela 3. Embora os percentuais não sejam tão altos, percebe-se que há diferenças entre o que é determinado pelo MDS e Secretarias Municipais e o que é executado pelo CRAS.

Os dados estão em consonância com o novo formato da política de enfrentamento que adota a inserção em SCFV e a pactuação do PETI. Dos 10 municípios participantes da pesquisa, oito pactuaram, o que explica por que há permanência do PETI. Todavia, o novo formato da política de enfrentamento no âmbito do SUAS baseia-se essencialmente nas ações em rede ou ações intersetoriais, através de Ações Estratégicas (AEPETI). Mas, considerando-se o ponto de corte de $20 \%$ nas respostas, as ações em Rede só foram abordadas nas estratégias das Secretarias Municipais pelos profissionais (21,5\%), revelando assim que as estratégias ainda se encontram significativamente localizadas em ações que integram benefícios e ações socioeducativas.

No caso do MDS, como as estratégias identificadas pelos dois segmentos de participantes foram as mesmas, os percentuais entre ambos são bem próximos. Há ainda que se destacar o percentual de $20 \%$ dos profissionais que não sabem se o MDS determina estratégias de enfrentamento ao trabalho infantil.

Tabela 3. Estratégias do MDS/Secretarias Municipais/CRAS

\begin{tabular}{|c|c|c|c|c|c|}
\hline \multicolumn{6}{|c|}{ Estratégias MDS } \\
\hline Gestores & $\mathbf{F}$ & $\%$ & Profissionais & $\mathbf{F}$ & $\%$ \\
\hline Inserção no SCFV & 13 & 39,4 & Inserção no SCFV & 26 & 40,0 \\
\hline Busca ativa & 8 & 24,2 & Inserção no PETI & 20 & 30,8 \\
\hline Encaminhamentos & 8 & 24,2 & Busca ativa & 15 & 23,1 \\
\hline Inserção no PETI & 8 & 24,2 & Oficinas & 14 & 21,5 \\
\hline Campanhas socioeduca & 8 & 24,2 & Campanhas socioeduca & 13 & 20,0 \\
\hline Oficinas & 7 & 21,2 & Não sabe & 13 & 20,0 \\
\hline Orientação & 7 & 21,2 & & & \\
\hline
\end{tabular}


Tabela 3. Continução

\begin{tabular}{|c|c|c|c|c|c|}
\hline \multicolumn{6}{|c|}{ Estratégias Secretarias Municipais } \\
\hline Gestores & $\mathbf{F}$ & $\%$ & Profissionais & $\mathbf{F}$ & $\%$ \\
\hline Inserção no SCFV & 19 & 57,6 & Inserção no SCFV & 40 & 61,5 \\
\hline Campanhas socioeduca & 10 & 30,3 & Inserção no PETI & 20 & 30,8 \\
\hline Acompanhamentos & 7 & 21,2 & Trabalho em rede & 14 & 21,5 \\
\hline \multicolumn{6}{|c|}{ Estratégias CRAS } \\
\hline Orientação/Palestras & 16 & 48,4 & Campanhas socioeduc & 26 & 40,0 \\
\hline Encaminhamentos & 12 & 36,4 & Oficinas & 21 & 32,3 \\
\hline Acompanhamentos & 9 & 27,3 & Acompanhamentos & 20 & 30,8 \\
\hline Inserção no SCFV & 9 & 27,3 & Inserção no SCFV & 17 & 26,2 \\
\hline Oficinas & 9 & 27,3 & Encaminhamentos & 16 & 24,6 \\
\hline
\end{tabular}

Fonte: Pesquisa Direta, 2016/2017

Ambos os segmentos de gestores e profissionais fizeram referências a um conjunto de estratégias de acompanhamento (gestores, $27,3 \%$ e profissionais, $30,8 \%$ ), visitas domiciliares (gestores, 24,2\%), identificação dos casos (gestores, 21,2\%) e busca ativa (profissionais, 23,1\%). São estratégias do CRAS que sinalizam ações com indivíduos ou famílias.

As estratégias desenvolvidas pelo CRAS também geram encaminhamentos para a Rede socioassistencial. $36,3 \%$ dos gestores e $24,6 \%$ dos profissionais fazem encaminhamentos (Tabela 3). No que se refere a esses encaminhamentos, os gestores $(21,2 \%)$ e profissionais $(15,4 \%)$ relataram que a maioria deles é direcionada ao Conselho Tutelar. Todavia, no novo formato da política de enfrentamento, o CREAS também é responsável pelo trabalho infantil, por se tratar de uma violação. Mas, apenas $15,2 \%$ dos gestores e $13,8 \%$ dos profissionais fizeram referências de encaminhamento para o CREAS. O encaminhamento para outras políticas setoriais foi referido: saúde, por $15,2 \%$ para profissionais e $9,3 \%$ por profissionais.

\section{Concepção dos Usuários sobre os Serviços do CRAS para Enfrentar o Trabalho Infantil}

Para tentar compreender a atuação do CRAS e SCFV, na concepção dos usuários dos serviços, foi questionado, através de uma questão aberta, por que motivo eles procuravam o CRAS (Tabela 4). A maioria dos participantes usuários procura o CRAS em busca de trabalho $(35,5 \%)$, inserir em cursos $(31,6 \%)$, solicitar benefício (30,2\%), por questão familiar (17,1\%), acompanhamento das crianças (15,8\%). As palestras e orientações ressaltadas pelos gestores e profissionais como estratégias do CRAS só foram referidas por $6,5 \%$ dos usuários.

Tabela 4. Motivo para Procurar O CRAS E SCFV

\begin{tabular}{lcc}
\hline Motivo & F & $\%$ \\
\hline Trabalho & 27 & 35,5 \\
Inserir em cursos & 24 & 31,6 \\
Solicitar Benefício & 23 & 30,2 \\
Por questão familiar & 13 & 17,1 \\
Acompanhamento das crianças & 12 & 15,8 \\
Orientação/Palestras & 5 & 6,5 \\
Encaminhamento & 1 & 1,3 \\
\hline
\end{tabular}

Fonte: Pesquisa Direta, 2016/2017.

Foi questionado aos usuários de quais atividades eles e suas famílias participam no CRAS. 35\% dos participantes usuários que têm seus filhos nas atividades do SCFV e no CRAS não participam de nenhuma atividade, $27,6 \%$ participam de cursos, $17,1 \%$ do PBF, $14,5 \%$ de benefícios eventuais. $61,1 \%$ dos usuários afirmaram que nos serviços do CRAS e SCFV de que participavam foi falado sobre o trabalho infantil; diferentemente, $32,9 \%$ dos usuários relataram que não falaram sobre o trabalho infantil. Dos $61,1 \%$ que afirmaram ter ouvido falar sobre o trabalho infantil, em respostas de múltipla escolha, $60,0 \%$ ouviram em palestra, $60,0 \%$, através de orientação de um profissional em visita familiar e 48,0\% foram informados em reuniões.

Questionou-se, também, aos usuários se o CRAS contribui para retirar crianças e adolescentes do 
trabalho infantil. Para $82,4 \%$, sim; e para $17,6 \%$, não. $36,1 \%$ dos usuários disseram que isso acontece por meio dos cursos oferecidos pelo CRAS, $34,4 \%$ responderam porque o CRAS retira crianças e adolescentes da rua e $24,6 \%$, que a retirada do trabalho infantil se dá porque o CRAS ocupa a mente.

\section{Discussão}

Ao analisar os dados biossociodemográficos dos gestores, profissionais e usuários verificou-se consonância com a literatura (Alberto et al., 2016; Alberto et al., 2017), revelando que o perfil dos usuários e profissionais que existia no PETI se mantém nos usuários e profissionais no novo formato do enfrentamento do trabalho infantil pela política de assistência social. A maioria dos participantes é do sexo feminino, os gestores e profissionais se autodeclaram pertencentes à etnia parda e os usuários, à etnia morena. A faixa etária predominante nos três grupos foi de 31 a 40 anos. Entre os usuários a escolaridade dominante foi do Ensino Fundamental incompleto; quanto à escolaridade da maioria dos gestores e profissionais, são graduados e pós-graduados para gestores, porém identificou-se a incoerência da existência de participantes ocupando o cargo de gestor, que possuem apenas o Ensino Médio.

Nesta pesquisa há mais similaridades entre os participantes gestores, profissionais e usuários. Maior número de participantes se autodeclararam pardos, negros e morenos. Difere de certo modo de Alberto et al. (2017), que haviam encontrado uma segmentação em dois grupos: educandos, família e educadores, que se autorreferenciaram como morenos ou negros, e coordenação, equipe técnica e professores, que se autorreferenciaram como brancos.

Mas, assemelha-se mais à literatura no que diz respeito ao sexo dos participantes (Alberto et al., 2016; Alberto et al., 2017), reproduzindo características e estereótipos de que as mulheres se cuidam mais do que os homens e de que cuidadores são na maioria mulheres; que nas situações de cuidado de si, como na saúde, há mais adesão de mulheres; assim, tanto usuários como profissionais são predominantemente mulheres (Pinheiro \& Couto, 2013). São estudos que revelam as crenças e os estereótipos de gênero nos serviços e políticas públicas de proteção básica (Couto \& Gomes, 2012).

$\mathrm{Na}$ escolaridade corrobora a literatura (Alberto et al., 2016; Alberto et al., 2017): educandos e famílias têm Ensino Fundamental incompleto, educador social tem Ensino Médio, equipe técnica e professores têm nível superior. No grupo de gestores o curso de graduação prevalente foi Psicologia e no de profissionais, o de Serviço Social. Aspecto relevante a ressaltar é a presença do profissional de Psicologia gerindo ou coordenando um segmento da política de Assistência Social, especificamente a política de proteção básica, o CRAS. Aspecto que está em consonância com o que Dantas e Oliveira (2014) identificaram: a inserção dos psicólogos na política de assistência social a partir da ampliação das redes de programas e serviços que compõem a proteção social básica.

Sobressai como estratégia determinada pelo Ministério e Secretarias Municipais, para gestores e profissionais, SCFV e PETI. Estratégias significativamente centralizadas em ações socioassistenciais e socioeducativas. Os dados estão em consonância com o eixo de proteção do novo formato da política de enfrentamento: perdura a inserção em serviços socioassistenciais (MDS, 2013). Faz sentido o destaque que dão ao SCFV, pois no âmbito da Proteção Social Básica, o desempenho do serviço socioeducativo passou a ser de responsabilidade do SCFV, que é ofertado no CRAS (MDS, 2010a), como também o destaque que dão ao PETI, porque no novo formato da política uma das ações é a pactuação do cofinanciamento entre Governo Federal, estados e municípios. Como alguns municípios onde foi realizada a pesquisa pactuaram o PETI, explica por que há permanência do PETI.

Todavia, no novo formato recomendado pela política de enfrentamento, embora tenha o SCFV, as ações socioassistenciais não têm a característica de ação educativa de contraturno e o PETI é substituído pelo AEPETI (Ações Estratégicas do PETI), que consiste em ações de articulação da Rede. As Ações Estratégicas do PETI (AEPETI), no âmbito do SUAS (Sistema Único de Assistência Social), têm mais quatro eixos além da Proteção Social. São eles: Informação e Mobilização; Defesa e Responsabilização; Identificação; Monitoramento. Mas, considerando-se os dados desta pesquisa, o ponto de corte de $20 \%$ nas respostas, as ações em Rede só foram abordadas nas estratégias das Secretarias Municipais pelos profissionais (21,5\%), revelando assim que, na percepção de gestores e profissionais, as estratégias ainda se encontram significativamente localizadas em ações que integram benefícios e ações socioeducativas ou socioassistenciais.

No novo cenário do Enfrentamento ao Trabalho Infantil pela Política de Assistência Social, o MDS determina que se incorporem ações de variadas políticas públicas (MDS, 2010b; MDS, 2013), articulação intersetorial do SGD e socioassistencial do território. O CRAS e o SCFV 
devem se articular com a Rede Socioassistencial, para ter ação potencializada (MDS, 2009; Monteiro, 2011). Mas isso não está ocorrendo na Paraíba, pelo menos não nos municípios estudados ou pelo menos não foi significativamente apresentado por gestores e profissionais como estratégias do MDS.

Esse dado é interessante: o Ministério de Desenvolvimento Social criou o PETI, reestruturou e promoveu mudanças e concebeu o SCFV. Mas, nas últimas determinações para enfrentamento ao trabalho infantil, recomenda articulação de políticas setoriais, do SGD e da rede socioassistencial. Os gestores e profissionais destacam como estratégias do MDS inserção no SCFV e PETI. Não ressaltam o conhecimento e aplicação dos aspectos reestruturados pelo MDS, embora quando se indaga sobre a capacitação, sobressaia a gestão da política.

Paradoxalmente, como destaque das estratégias do CRAS são dadas as campanhas socioeducativas (pelos gestores) e as palestras (pelos profissionais) e, em menor percentual, ações com indivíduos ou famílias: acompanhamento, visita familiar, identificação de casos. Embora gestores e profissionais não tenham dado um grande destaque ao encaminhamento, ele se fez presente como estratégia. $O$ encaminhamento configura como ação entre setores, logo possibilita ação em Rede, entre políticas setoriais. Indaga-se: se as estratégias do MDS e Secretarias são SCFV e PETI, como então o CRAS faz campanhas e palestras? Que papel e lugar ocupam as ações com os indivíduos e famílias? Como o CRAS tem a função de atuar no território e como porta de entrada para a política de proteção, não foi possível separar, na pesquisa, o contexto dessas ações com indivíduos e famílias no âmbito da política básica como um todo do foco para o enfrentamento ao trabalho infantil.

Esta pesquisa identifica que há no mínimo hiatos, vácuos, dissonâncias e contradições entre MDS, Secretarias Municipais, gestão, formação e atuação dos profissionais no enfrentamento ao trabalho infantil. Executam estratégias pautadas em modelos anteriores de enfrentamento, a exemplo do PETI, ou ressaltam-se estratégias centradas em inserção em programas socioassistenciais como o SCFV, em detrimento das atualmente determinadas, estratégias de Redes e intersetorialidade. Mantém-se uma concepção do enfrentamento ao trabalho infantil como exclusiva da política de assistência social (Alberto \& Yamamoto, 2017) e coloca-se como foco da política de assistência social a indigência (Behring $\&$ Boschetti, 2011). E a nova política revela o que a literatura (Bonamigo, et al., 2015; Cacciamalli et al., 2010;
Gouveia, 2013) já vem demonstrando: a inadequação desses programas para enfrentar o trabalho infantil.

É tão invisível o enfrentamento ao trabalho infantil pelo CRAS, que a maioria dos usuários que tem filhos informou não participar de nenhuma atividade. Entretanto, disseram ter crianças ou adolescentes participando do PETI e do PROJOVEM no CRAS. A inserção deles nos referidos programas, segundo informaram, foi para ajudar na aprendizagem. Mas auxiliar na aprendizagem se configurou como objetivo do PETI no início do programa, em 2001 (MPAS, 2001). Entretanto, é interessante analisar que esse objetivo se mantenha para as famílias 15 ou 16 anos após, o que leva os pesquisadores a relacionar com outra informação: de que a principal estratégia do CRAS, para 53,8\% dos profissionais, são palestras, então é possível que essa informação seja repassada nas palestras.

Talvez se sobressaia a inserção em programas que conjugam benefício, escolaridade e atividades socioassistenciais, porque pode decorrer daquilo que Cavalcanti et al. (2013) e Bonamigo et al. (2015) identificam que vários autores defendem que as contrapartidas são mais importantes do que a transferência de renda, porque aumentam a frequência escolar e incentivam o aumento do capital humano. Assemelha-se aos estudos de Cacciamalli et al. (2010), que identificam nos estudos, na América Latina, que a avaliação dos programas de transferência de renda apresenta resultados positivos, quando têm condicionalidades realizadas com a educação e saúde. Identificam também que a transferência de renda não apresenta impacto significativo sobre o trabalho infantil, mas sobre a escolaridade. O que está de acordo com a pesquisa de Gouveia (2013), que revela que a inserção de crianças e adolescentes no PETI proporciona mudanças positivas tanto na vida como no comportamento, na socialização, no aprendizado e rendimento escolar.

No caso da pesquisa de Alberto e colaboradores (2017), os motivos de inserção no PETI ligavam-se às necessidades das crianças e adolescentes, tais como reforço escolar e não ter com quem ficar, mas, nesta pesquisa, ligam-se às necessidades da família ou dos adultos, como buscar trabalho e fazer cursos. Então, o CRAS é mais visível e procurado pelas necessidades dos adultos e da família e menos para crianças e adolescentes. Mesmo o SCFV, teoricamente, encontrando-se dentro ou ligado ao CRAS, a procura do CRAS para obter inserção de crianças e adolescentes no SCFV não foi abordada. Ao procurar o CRAS, devido às necessidades das crianças e adolescentes, os usuários usam o 
termo "acompanhamento de crianças". A semelhança de Alberto e colaboradores (2017) é que na pesquisa deles o PETI não era visível como ferramenta de combate ao trabalho infantil; e nesta pesquisa o SCFV e o CRAS não são visíveis para os usuários como ferramentas de enfrentamento ao trabalho infantil.

\section{Considerações finais}

Revela-se, assim, que o novo modelo de política de enfrentamento não diverge do modelo anterior, o perfil de gestores, profissionais e usuários é semelhante. As mudanças e junções de políticas promoveram o reordenamento que criou o modelo de atuação centrado no fortalecimento de vínculos e articulação de políticas intersetoriais com o SGD e a rede socioassistencial. Mas, apenas $20 \%$ e $15 \%$, sucessivamente, fazem articulação socioassistencial (serviços e equipamentos) e intersetorial (de políticas setoriais), assim como não aparecem na pesquisa as ações do AEPETI. Não é claro para gestores, profissionais e usuários, o foco do CRAS e SCFV no enfrentamento do trabalho infantil. Não há novidade no cenário no enfrentamento do trabalho infantil pela política de assistência social. Mas, o Estado, conforme a Constituição Federal, no Artigo 27, tem o papel de garantir os direitos e a proteção de crianças e adolescentes. Aspecto imprescindível para tal é a oferta, garantia e execução de políticas públicas de geração de trabalho e renda para as famílias, educacionais, de saúde e de assistência social para as crianças e adolescentes, com o objetivo de enfrentar o trabalho. Significa a existência de recursos nos orçamentos públicos, o que requer, por sua vez, a ação dos Conselhos de Direitos no planejamento e monitoramento e o movimento de todo o Sistema de Garantia de Direitos (SGD) e da sociedade. Conclui-se pela necessidade de avançar nas pesquisas sobre o enfrentamento ao trabalho infantil pelos Conselhos e o SGD, limitação deste estudo.

\section{Referências}

Alberto, M. F. P., Pessoa, M. C. B., Costa, R. R., Belém, K. K. G., \& Silva, S. L. G. (2016). Programa de Erradicação do Trabalho Infantil: concepções de educandos e famílias. Psicologia: Ciência e Profissão, 36(2), 458-470. doi: 10.1590/1982-3703001842013

Alberto, M. F. P., Viana, H. A., Santos, E. C., Patriota, G. F. R., \& Bittencourt, N. F. B. (2017) Programa de Erradicação do Trabalho Infantil e garantia de direitos. Revista Direitos Fundamentais e Democracia, 22(1), 196-227. doi: 10.25192/issn.1982-0496.rdfd. v22i1658
Alberto, M. F. P., \& Yamamoto, O. H. (2017). Quando a educação não é solução: política de enfrentamento ao trabalho infantil. Temas em Psicologia, 25(4), 1677-1691. doi: 10.9788/TP2017.4-10Pt

Behring, E. R., \& Boschetti, I. (2011). Política social: fundamentos e história. São Paulo: Cortez.

Bichir, R. (2016). Novas agendas, novos desafios reflexões sobre as relações entre transferência de renda e assistência social no Brasil. Novos estudos CEBRAP, 35(1), 111-136. doi: 10.25091/ s0101-3300201600010006

Bonamigo, I. S., Tondin, C. F., Szytko, M., Moro, E., Ramos, T., \& Biazi, G. (2015). Circulação de crianças e adolescentes na rede tecida pelo Programa de Erradicação do Trabalho Infantil (PETI). Estudos \& Pesquisas em Psicologia, 15(spe), 1345-1362. doi: 10.12957/epp.2015

Cacciamali, M. C.; Tatei, F.; \& Batista, F. N. (2010). Impactos do programa Bolsa Família Federal sobre o trabalho infantil e a frequência escolar. Economia Contemporânea, 14(2), 269-301. doi: 10.1590/ S1415-98482010000200003.

Carmo, M. E., \& Guizardi, F. L. (2017). Desafios da intersetorialidade nas políticas públicas de saúde e assistência social: uma revisão do estado da arte. Physis: Revista de Saúde Coletiva, 27(4), 1265-1286. doi: 10.1590/s0103-73312017000400021

Cavalcanti, D. M., Costa, E. M., \& Silva, J. L. M. (2013). Programa Bolsa Família e o Nordeste: impactos na renda e na educação, nos anos de 2004 e 2006. Revista Economia Contemporânea, 17(1), 99-128. doi:10.1590/S1415-98482013000100004

Couto, M. T., \& Gomes, R. (2012). Homens, saúde e políticas públicas: a equidade de gênero em questão. Ciência \& Saúde Coletiva, 17(10), 2569-2578. doi: 10.1590/S1413-81232012001000002

Dantas, C. M. B., \& Oliveira, I. F. (2014). As cidades pequenas como território da ação do psicólogo: desafios teóricos e metodológicos. In M. Dimenstein \& J. F. Leite (Orgs.), Psicologia em Pesquisa: cenários de práticas e criações (pp. 93-117). Natal, RN: EDUFRN.

Gouveia, C. N. N. A. (2013). Avaliação da eficácia e efetividade do programa de erradicação do trabalho infantil a partir da perspectiva dos usuários e agentes (Tese de Doutorado, Universidade Federal de Paraíba. João Pessoa, PB). Recuperado de https://repositorio. ufpb.br/jspui/handle/tede/6977

Lei oㅜ 10.836, de 9 de janeiro de 2004 (2004, 9 de janeiro). Cria o Programa Bolsa Família e dá outras providências. Diário Oficial da União, seção 1.

Mendonça, M. H. M. (2002). O desafio da política de atendimento à infância e à adolescência na construção de políticas públicas eqüitativas. Cadernos de Saúde Pública, 18(Supl.), S113-S120. doi: 10.1590/S0102-311X2002000700012

Ministério da Previdência e Assistência social - MPAS (2001). Secretaria de estado de assistência social. Portaria $n^{\circ} 458$, de 4 de outubro de 2001. Estabelece diretrizes e normas do programa de erradicação do trabalho infantil - PETI. Brasília: Secretaria Nacional de Assistência Social.

Ministério do Desenvolvimento Social e Combate à Fome - MDS (2004). Programa de erradicação do Trabalho Infantil - Cartilha do PETI. Brasília, DF: Autor.

Ministério do Desenvolvimento Social e Combate à Fome - MDS (2005). Ministério do Desenvolvimento Social e Combate à Fome - MDS. Portaria № 666, de 28 de Dezembro de 2005. Disciplina a integração entre o Programa Bolsa Família e o Programa de Erradicação 
do Trabalho Infantil. Recuperado de http://www.mds.gov.br/suas/ menu_superior/legislacao1

Ministério do Desenvolvimento Social e Combate à Fome - MDS (2009). Orientações técnicas: Centro de Referência de Assistência Social CRAS. Brasília, DF. Recuperado de http://www.mds.gov.br/webarquivos/ publicacao/assistencia_social/Cadernos/orientacoes_Cras.pdf

Ministério do Desenvolvimento Social e Combate à Fome - MDS (2010a). Orientações técnicas sobre o Serviço de Convivência e Fortalecimento de Vínculos para crianças e adolescentes de 6 a 15 anos: prioridade para crianças e adolescentes integrantes do Programa de Erradicação do Trabalho Infantil. Brasília, DF: Secretaria Nacional de Assistência Social. Recuperado de http://www2.maringa.pr.gov.br/sistema/arquivos/fcd77625ea9a.pdf

Ministério do Desenvolvimento Social e Combate à Fome - MDS (2010b). Orientações técnicas: Gestão do Programa de Erradicação do Trabalho Infantil no SUAS. Brasília, DF: Secretaria Nacional de Assistência Social. Recuperado de https://www.mds.gov.br/webarquivos/publicacao/assistencia_social/Cadernos/orientacao_gestao_ PETI.pdf

Ministério do Desenvolvimento Social e Combate à Fome - MDS (2013). Ministério do Desenvolvimento Social e Combate à Fome - MDS. Resolução no 008, 18 de abril de 2013. Dispõe sobre as ações estratégicas do Programa de Erradicação do Trabalho Infantil - PETI no âmbito do Sistema Único da Assistência Social - SUAS e o critério de elegibilidade do cofinanciamento federal para os exercícios de 2013/2014 destinado a Estados, Municípios e Distrito Federal com maior incidência de trabalho infantil e dá outras providências. Brasília, DF. Recuperado de http://blog.mds.gov.br/redesuas/wp-content/
uploads/2015/10/Resolu\%C3\%A7\%C3\%A3o-n\%C2\%BA-08-2013CNAS-18-04-20131.pdf

Monteiro, S. R. R. P. (2011). O Serviço social no Centro de Referência de Assistência Social-CRAS: para avançar na consolidação da política de assistência social na perspectiva de direito. Trabalho apresentado no V Jornada Internacional de Políticas Públicas, São Luís, MA. Recuperado de http://www.joinpp.ufma.br/jornadas/ joinpp2011/CdVjornada/JORNADA_EIXO_2011/IMPASSES_E_ DESAFIOS_DAS_POLITICAS_DA_SEGURIDADE_SOCIAL/O_ SERVICO_SOCIAL_NO_CENTRO_DE_REFERENCIA_DE_ ASSISTENCIA_SOCIAL_CRAS.pdf

Pinheiro, T. F., \& Couto, M. T. (2013). Sexualidade e reprodução: discutindo gênero e integralidade na Atenção Primária à Saúde. Physis: Revista de Saúde Coletiva, 23(1), 73-92. doi: 10.1590/ S0103-73312013000100005

Procuradoria Regional do Trabalho - $7^{a}$ Região (2009). Ranking Nacional Do Trabalho Infantil (5 a 17 ANOS). Recuperado de http:// www.conselhodacrianca.al.gov.br/sala-de-imprensa/publicacoes/ trabalho-infantil

Romagnoli, R. C. (2018). As relações entre as famílias e a equipe do CRAS. Fractal: Revista de Psicologia, 30(2), 214-222. doi: 10.22409/1984-0292/v30i2/5516

Rua, M. G. (2007). Avaliação da integração do Programa de Erradicação do Trabalho Infantil (PETI) ao Programa Bolsa Família $(P B F)$. Brasília, DF: Fórum Nacional de Prevenção e Erradicação do Trabalho Infantil - FNPETI.

Silva, M. O., \& Yaszbek, M. C.,\& Giovanni, G. (2008). A Política Social Brasileira no Século XXI: a prevalência dos programas de transferência de renda. São Paulo: Cortez.

1. O projeto do qual se originou este artigo foi financiado pelo CNPq, em Edital Universal de no 14/2014, Processo 461884/2014-3. A primeira autora obteve bolsa produtividade do CNPq. Dois estudantes tiveram Bolsa PIBIC pelo CNPq/UNIV.

Maria de Fatima Pereira Alberto, Doutora em Sociologia pela Universidade Federal de Pernambuco - UFPE, Pós-Doutora em Psicologia pela Universidade Federal do Rio Grande do Norte - UFRN, é Professora Titular da Universidade Federal da Paraíba - UFPB. Endereço para correspondência: Departamento de Psicologia CCHLA - Bloco Humanístico, Campus I - Castelo Branco I, Universidade Federal da Paraíba, João Pessoa - PB, CEP: 58051-900. Telefone: (83) 98821-2390. Email: jfalberto89@gmail.com

Ana Lúcia dos Santos França, Psicóloga pela Universidade Federal da Paraíba - UFPB. Email: analucya_21@hotmail.com

Gustavo de Sousa Silva, Psicólogo pela Universidade Federal da Paraíba - UFPB. Email: gugstavo01@gmail.com

Claudio Marques Trindade, Psicólogo pela Universidade Federal da Paraíba - UFPB. Email: claudiozxz@gmail.com

Rebeca Kelly Gomes da Silva, Psicóloga pela Universidade Federal da Paraíba - UFPB. Email: rebecakelly3@gmail.com

Recebido em 08.mai.18 Revisado em 23.ago.19 Aceito em 31.dez.19 